\title{
Discursos (Sobre)Viver nos Territórios em \\ Risco da Região Metropolitana do Recife
}

\author{
Juliana Catarine Barbosa da Silva ${ }^{1}$ \\ ${ }^{1}$ Universidade de Pernambuco, PE, Brasil.
}

\author{
Jaileila de Araújo Menezes ${ }^{1}$ \\ ${ }^{1}$ Universidade Federal de Pernambuco, PE, Brasil.
}

Resumo:A presente pesquisa objetiva analisar e debater os discursos produzidos por usuárias(os) do Sistema Nacional de Proteção e Defesa Civil, residentes na Região Metropolitana do Recife, no que diz respeito à vida nos territórios em risco. O estudo está inserido no conjunto de pesquisas que buscam compreender os fenômenos socioculturais que envolvem a questão do risco, e suas implicações para os processos de subjetivação das pessoas nos contextos marcados por emergências e desastres. Desenvolvemos uma metodologia qualitativa, como referenciais epistêmico-metodológicos adotamos os estudos foucaultianos sobre discurso e a Psicologia Discursiva de origem inglesa. Realizamos entrevistas semiestruturadas com a participação de três homens e doze mulheres usuárias(os) da defesa civil e beneficiárias(os) do auxílio-moradia. Os discursos produzidos ressaltaram um território marcado por um sistema de gerenciamentos de riscos deficitário e pouco efetivo, sendo que a pobreza e a dificuldade de acesso a serviços públicos básicos são demandas centrais das pessoas que nele habitam. Identificamos também estratégias de resistência, que mesmo fragilizadas, buscam suprir a ausência efetiva do Estado nesses espaços. A questão social é uma temática central no contexto pesquisado, produz marcas profundas naquilo que se define como risco e, por conseguinte, na vida das pessoas que habitam os territórios permeados por ele.

Palavras-chave: Risco, Desastres, Territórios, Processos de Subjetivação.

\section{Discourses (About) Living in Territories at Risk of the Metropolitan Region of Recife}

\begin{abstract}
This study analyzes the discussions produced by users of the National System for Civil Protection and Defense by residents of Recife's Metropolitan Region regarding survival in territories at risk. It is part of a set of projects which seek to understand socio-cultural phenomena where the matter of risk is involved and its implications for processes of how people interiorize emergencies and disasters in their respective contexts. A qualitative methodological approach was adopted. We used Foucault's study on discourse and the English school of Discursive Psychology as epistemic-methodological frameworks. Semi-structured interviews were conducted with the participation of 12 women and 3 men who were end-users of civil defense and beneficiaries of housing assistance. The generated discussions indicated a territory marked by a system of risk management which was deficient and very ineffective, as poverty and difficult access to basic public services are demands pertaining to people who live there. We also identified strategies for resistance which, even when they became fragile, sought to overcome the state's lack of presence in these scenarios. Social issues constitute a central subject for the context analyzed, as they have a profound impact upon what is defined as risk and for the people who live in territories permeated by this risk.
\end{abstract}

Keywords: Risk, Disasters, Territories, Subjectivation Processes. 


\title{
(Discursos (Sobre)Vivir en los Territorios en Riesgo de la Región Metropolitana de Recife
}

\begin{abstract}
Resumen: La presente investigación objetiva analizar y debatir los discursos producidos por usuarias/os del Sistema Nacional de Protección y Defensa Civil, residentes en la Región Metropolitana de Recife, en lo que se refiere a la vida de las personas en territorios en riesgo. El estudio está insertado en un conjunto de investigaciones que buscan comprender los fenómenos socioculturales que involucran las cuestiones de riesgo, y sus implicaciones para los procesos de subjetivación de las personas en los contextos marcados por emergencias y desastres. Desarrollamos una metodología cualitativa, como referencias epistémico-metodológicas, y adoptamos los estudios foucaultianos sobre discurso y la Psicología Discursiva de origen inglesa. Realizamos entrevistas semiestructuradas con la participación de tres hombres y doces mujeres usuarios/as de defensa civil y beneficiarios/as del programa auxilio vivienda. Los discursos producidos apuntan un territorio marcado por un sistema de gerenciamientos de riesgos deficiente y poco efectivo, siendo que la pobreza y la dificultad al acceso de servicios públicos básicos son las demandas centrales de las personas donde habitan. Identificamos también estrategias de resistencia, que aun fragilizadas buscan suprimir la ausencia efectiva del Estado en esos lugares. La cuestión social es una temática central del contexto encuestado, produciendo marcas profundas en lo que se define como riesgo y, por consiguiente, en la vida de las personas que habitan en los territorios impregnados por estos riesgos.
\end{abstract}

Palabras clave: Riesgo, Desastres, Territorios, Procesos de Subjetivación.

\section{Introdução}

Este artigo faz parte de uma pesquisa maior, que buscou compreender os múltiplos discursos sobre o risco no contexto do Sistema Nacional de Proteção e Defesa Civil (Sinpdec) ${ }^{1}$. Alguns dos elementos que chamaram atenção são as relações estabelecidas entre as pessoas entrevistadas e o viver nas áreas de risco, como constroem suas estratégias de sobrevivência em um contexto de extrema vulnerabilização, pobreza e precarização. Os caminhos percorridos por essas pessoas nos territórios marcados pelo risco imprimem marcas profundas a suas histórias de vida e, por conseguinte, a seus processos de subjetivação. Nesse sentido, pretende-se analisar e debater os discursos produzidos por usuárias(os) do Sinpdec, residentes na Região Metropolitana do Recife (RMR), no que diz respeito à vida nos territórios em risco.
Conforme debatido em Silva e Menezes (2016), na Psicologia, a temática dos riscos no contexto das emergências e desastres tem percorrido os mais variados caminhos, passando por questões como a percepção de risco, geralmente discutida a partir de constructos mais cognitivistas (Paulino \& Lopes, 2010), e pelo debate sobre os transtornos de estresse pós-traumático decorrentes da exposição de pessoas à situações de risco, contemplado por estudiosos da Psicologia Clínica (Franco, 2005). Dentre esses elementos clínicos o fenômeno da resiliência (Brandão et al., 2011) é largamente citado em Psicologia. Destacam-se ainda os pesquisadores que investigam as questões socioculturais que circundam a temática do risco (Spink, 2014, pp. 2-3).

Este texto se aproxima mais do último grupo de pesquisas, situadas no campo da Psicologia Social.

\footnotetext{
${ }^{1}$ O Sinpdec é o instrumento que concentra no Brasil a maioria das intervenções sobre riscos no contexto das emergências e desastres. Essa instituição surgiu a partir de demandas militares no contexto da Segunda Guerra Mundial e historicamente foi convocada, pensada ou problematizada em períodos marcados por grandes catástrofes. Nas últimas duas décadas, o sistema tem se modificado, aumentando o número de unidades nos estados e municípios, contudo continua, na maioria delas, instável e precarizado. A defesa civil é definida pelo Decreto ${ }^{\circ}$ 7.257, de 4 de agosto de 2010, como "o conjunto de ações preventivas, de socorro, assistenciais e recuperativas destinadas a evitar desastres, minimizar seus impactos para a população e restabelecer o cotidiano social”.
} 
Consideramos, por exemplo, que a contraposição de termos como resiliência (Brandão et al., 2011) e resistência (Foucault, 2013b) tem sido um movimento importante para localizarmos o tipo de debate que tem nos interessado no tocante aos estudos sobre o risco. Mesmo que não representem ideias necessariamente opostas, observamos empregos distintos entre as ideias de resistência e resiliência. Por exemplo, as reflexões que tratam do gerenciamento dos riscos no contexto das emergências e desastres a partir do construto resiliência (Brandão et al., 2011; Souza, 2011) - mesmo aquelas voltadas para a investigação dos grupos resilientes - centram seus esforços em compreender como, mesmo estando em extrema dificuldade, as pessoas conseguem adaptar-se. Já a resistência, conceito do qual temos nos aproximado, considera as possibilidades socioculturais de mobilidade das pessoas dentro das relações de poder, sendo por nós pensado a partir daqueles que não se adaptam e por isso tentam mudar o que está historicamente posto (Foucault, 2004).

Foucault (2013b) considera que as práticas de resistência não são exteriores às relações de poder, mas perpassam-nas, sendo elementos que proporcionam multiplicidade a essas relações. O poder só pode existir, enquanto tal, a partir de uma diversidade de pontos de resistência que permitem sua mobilidade e sua perspectiva relacional. Nesse sentido, do mesmo modo que o poder atravessa diversas camadas do tecido social, os pontos de resistência também o fazem, perpassando aparelhos e instituições. As práticas de si, as rupturas e as resistências não são invenções individuais, elas constituem esquemas que são encontrados pelos sujeitos e "que lhe são propostos, sugeridos, impostos por sua cultura, sua sociedade e seu grupo social" (Foucault, 2004, p. 276).

É importante frisarmos que as perspectivas discursivas que fundamentam o presente texto, conforme será melhor debatido mais adiante, compreendem os discursos como construções sociais situadas e determinadas historicamente. Nesse sentido, ao falarmos de risco, utilizamos como referência as reflexões desenvolvas por Spink et al. (2008), que identificou três dicionários específicos para tratar o tema: risco-perigo, risco-probabilidade, e risco-aventura; contudo, em relação aos estudos sobre defesa civil, há prevalência da ideia de risco-perigo, ou seja, do evento que pode acarretar prejuízos e danos. Nesse sentido, nossos achados corroboram os estudos de
Douglas (1996), quando afirma que a despeito de uma multiplicidade de discursos sobre o risco, o termo, em nosso modelo de sociedade, tem cada vez mais adquirido sentidos negativos.

O constructo emergência, por sua vez, pode ser brevemente definido como "1. Situação crítica; acontecimento perigoso ou fortuito; incidente. 2. Caso de urgência" (Brasil, 2017, p. 25). Os sentidos de desastre, por seu modo, podem ser problematizados de diversas formas, desde as classificações que o definem a partir de sua origem (Brasil, 2017) até mesmo as que preferem defini-lo de um ponto de vista mais sociológico, como buscaremos aqui pontuar. Destacamos a divisão entre desastres intensivos e extensivos. Enquanto os primeiros se referem aos desastres de baixa frequência, mas geograficamente concentrados e com grande potencial de impacto; os segundos caracterizam-se por ocorrerem com maior frequência e provocarem menores danos. Os desastres extensivos correspondem a $97 \%$ dos eventos relacionados ao clima, com alta frequência e números não significativos de óbitos; porém são responsáveis por grande proporção de danos à infraestrutura local e às habitações e condições de vida das comunidades e sociedades mais pobres. Os desastres extensivos são facilmente incorporados à "normalidade" das idiossincrasias urbanas, tornando-se potencialmente perigosos ao passo que são encarados como inofensivos e naturais. No entanto, devido à falta de atenção e monitoramento, muitos deles se transformam em potenciais desastres intensivos e causam danos em grandes proporções (Freitas et al. 2012).

Nesse sentido, ao tratarmos do tema risco atrelado à redução de desastres, precisamos considerar as relações das práticas político-institucionais, da circulação dos discursos e dos jogos de linguagem. Nas imbricações desses fenômenos, formam-se estratégias que, em muitos casos, inviabilizam a construção de um território seguro para as pessoas pobres, assim como desqualificam esses grupos para lidar com sua própria condição de vulnerabilização (Valencio, 2010).

Como psicólogas, não podemos deixar de compreender a marca social, cultural e econômica que perpassa a questão dos desastres, principalmente quando se vislumbra o contexto nacional. Por exemplo, entre 1970 e 2010, a proporção da população mundial que vivia em bacias hidrográficas sujeitas a inundações aumentou $114 \%$; já nas regiões costeiras expostas a ciclones, o aumento foi de $192 \%$. 
Enfatiza-se ainda que a elevada densidade populacional representa um condutor do risco, no qual a qualidade das moradias, a infraestrutura e os serviços são deficientes (Escola Nacional de Saúde Pública Sérgio Arouca, 2013).

Segundo o relatório Poverty \& death: disaster mortality (1996-2015), do Centre for Research on the Epidemiology of Disaster (CRED) e do United Nations Office for Disaster Risk Reduction (UNISDR) (2016), $90 \%$ de 1,35 milhão de pessoas que morreram em decorrência dos mais de 7 mil desastres oficialmente registrados são de países considerados com baixa ou média renda. Considera-se ainda que muitos dos eventos adversos que ocorrem não chegam a ser registrados por órgãos oficiais, por diversas dificuldades relativas aos processos de notificação existentes.

No Brasil, um dos maiores promotores de desastres é a inexistência ou o manejo inadequado de recursos hídricos, seja pelas questões relativas aos períodos de seca e estiagem, seja pelas enxurradas. Segundo dados do Ministério da Integração Nacional, em 2013², a região brasileira mais afetada por desastres foi a Nordeste, sendo a seca a principal problemática a ser enfrentada nessa parte do país. No contexto da RMR, local onde foi realizada a presente pesquisa, além das questões relativas a alagamentos e enchentes, os deslocamentos de massa estão fortemente relacionados aos sinistros. Os movimentos de massa - também conhecidos como deslizamentos - podem ser definidos como: "o processo pelo qual o material rochoso se move sob a ação da força da gravidade, necessariamente sob efeito de rupturas de solo e/ou rochas" (Ministério da Integração Nacional, 2014, p. 51).

Nesse sentido, o risco no contexto pesquisado não é qualquer tipo de risco. O Sinpdec atua em territórios permeados pela extrema pobreza e pela precarização das condições de vida, seus profissionais atendem diariamente pessoas cujas vidas são fortemente marcadas por essas questões.

Partimos do pressuposto de que o gerenciamento dos riscos de emergências e desastres influencia diretamente a vida nos territórios classificados como estando em risco pela defesa civil, imprimindo marcas singulares nos processos subjetivos daquelas(es) que circulam nesses espaços. Essa circulação caracterizada pela busca de segurança em meio aos territórios em risco também é permeada por resistências, pela mobilização contra os modelos hegemônicos de gestão dos riscos e da vida.

Para construir algumas reflexões sobre a referida temática e, por conseguinte, pensar nas implicações que tais questões demandam à psicologia, realizaremos inicialmente uma reflexão sobre os territórios e os processos de subjetivação. Posteriormente, apresentaremos nossos percursos metodológicos, seguidos da análise e discussão do material produzido durante a pesquisa.

\section{O território e os processos de subjetivação}

Para as(os) psicólogas(os) que se propõem a atuar e problematizar a questão das emergências e desastres, é fundamental ampliar o olhar sobre a questão para além das demandas de saúde mental nos períodos pós-acidentes. É necessário compreender as pessoas, suas relações com o espaço individual e coletivo, além das múltiplas questões sociais, políticas e afetivas que envolvem o tornar-se sujeito em contextos de extrema pobreza e precarização. Conforme recomenda o Conselho Federal de Psicologia (2013) aos profissionais que atuam no contexto das emergências e desastres, é preciso promover debates e intervenções baseadas na garantia de direitos e que não busquem vitimizar ou patologizar a população afetada.

A dimensão afetiva que permeia a construção do espaço de moradia é outra questão muito delicada e extremamente invisibilizada pelos saberes peritos (Giddens, 1991), que restringem suas análises ao contexto estrutural e, conforme sinaliza Koga (2009), desqualificam os saberes e afetos daqueles que habitam as áreas de risco. Para Vieira (2004), o lugar, principalmente quando se trata do local de nascimento ou construção de vínculos familiares, é extremamente significativo na maioria das culturas. A construção do espaço de moradia vai além dos investimentos financeiros, perpassando questões afetivas e identitárias, que tornam a remoção de pessoas, mesmo que de áreas de risco, uma questão extremamente complexa.

O lugar comporta ainda as redes de apoio social. Essas instâncias são definidas por Sluzki (1997) como o conjunto de relações que as pessoas compreendem como significativas, no qual podem estar contidos

${ }^{2}$ Até outubro de 2016, não identificamos no site no Ministério da Integração Nacional as publicações referentes aos anuários de 2014 e 2015. 
familiares, amigos, vizinhos, companheiros de trabalho e de escola. As redes de apoio social contribuem para o enfretamento de problemáticas individuais e coletivas.

Partindo da compreensão de que o meio físico é um fator essencial para compreensão de quem somos e de como agimos no mundo, pensar as relações entre as pessoas e os riscos, no contexto pesquisado, é essencial para compreender o viver nos territórios marcados pelo risco de desastres. Como intermediários dessa relação encontramos o Sinpdec, representante do Estado, que nas comunidades atua no gerenciamento do risco de desastres.

Essa instituição, conforme apontado em Silva (2017) e em Valencio, Siena, Marchezine e Gonçalves (2009), tem produzido interpretações limitadas sobre o tema dos riscos, supervalorizando os fenômenos naturais ou mesmo culpabilizando as(os) moradoras(es) por produzirem os sinistros. Silva (2017) observa ainda que no contexto do Sinpdec pouco se tem debatido sobre as multicausalidades dos desastres, como, por exemplo, as questões relativas à extrema desigualdade social presente no país, que expulsa diariamente as pessoas pobres para áreas de instabilidade estrutural e climática. Nesse sentido, sinaliza-se que o discurso do risco tem atingido diretamente o cotidiano das pessoas que residem nos territórios gerenciados pelo Sinpdec, interferindo na forma como elas compreendem a si e ao espaço em que habitam.

Observa-se nesse cenário que a defesa civil enquanto instituição possui um papel central na forma como o gerenciamento do risco aplica-se nos territórios em que está presente. Tal constatação permite problematizar o papel do referido órgão nos processos de subjetivação presentes nos territórios em risco. Aqui tomamos a definição de processos de subjetivação trazida por Bert (2013) a partir de seus estudos da obra de Michel Foucault, quando este afirma que os processos de subjetivação localizam-se em uma posição intermediária entre subjetivo e objetivo e também entre individual e institucional, possibilitando compreender como o sujeito da prática pode ser delimitado, até mesmo em ação. A subjetivação e a política estão estreitamente relacionadas, tendo em vista que o foco dos processos subjetivos está voltado para os modos como cada pessoa encontra a si mesma, se conduz e se governa.

Para Veiga-Neto (2007), Foucault propõe que os processos de subjetivação se dão a partir dos modos de investigação, das práticas divisórias e dos modos de transformação que outros aplicam e que nós aplicamos a nós mesmos. Para Foucault (2013b), o processo de objetivação do sujeito perpassa as relações de poder, não sendo possível considerar que os mecanismos de sujeição estão separados dos processos de exploração e dominação. Portanto o Estado apresenta-se como estrutura política que, de modo peculiar, utiliza técnicas de individualização e totalização para o controle das populações. Essa força totalizadora, mas também individualizante, faz do Estado uma estrutura política extremamente forte no modelo de sociedade atual. $\mathrm{O}$ autor considera o Estado como "a matriz moderna da individualização ou mesmo uma nova forma do poder pastoral" (Foucault, 2013b, p. 281). Tal entidade traduz agora a lógica da salvação em questões como saúde, bem-estar, segurança, proteção contra acidentes, entre outros objetivos que capturam as subjetividades. Nesse contexto, ao passo que se identifica o processo de subjetivação promovido pelo Estado, questiona-se a possibilidade de nos desvencilharmos dele e construirmos outras estruturas e processos.

Para Foucault (2013b):

o problema político, ético, social e filosófico de nossos dias não é tentar libertar o indivíduo do Estado nem das instituições do Estado, porém nos libertarmos tanto do Estado quanto do tipo de individualização que a ele se liga. Temos que promover novas formas de subjetividade através da recusa desse tipo de individualidade que nos foi imposto há vários séculos (p. 283).

Nesse sentido, temos compreendido que o Sinpdec se apresenta nos territórios em risco como parte de um dispositivo ${ }^{3}$ de segurança que atua diretamente na produção dos sujeitos do risco. Ao definir

\footnotetext{
${ }^{3}$ Utilizamos no presente texto a noção foucaultiana de dispositivo: um conjunto decididamente heterogêneo que engloba discursos, instituições, organizações arquitetônicas, decisões regulamentares, leis, medidas administrativas, enunciados científicos, proposições filosóficas, morais, filantrópicas. Em suma, o dito e o não dito são os elementos do dispositivo. O dispositivo é a rede que se pode estabelecer entre estes elementos. (Foucault, 2005, p. 244). Os dispositivos de segurança, por sua vez, são compreendidos por Foucault (2008) como as estratégias, utilizadas pelo Estado, para o controle da população no contexto da biopolítica. Para o autor quando a população se apresenta como questão emergente, a segurança configura-se como dispositivo integrador de múltiplos elementos, tais “como a produção, a psicologia, os
} 
quais áreas devem ou não ser consideradas de risco, ao ocultar determinadas problemáticas, como as questões sociais, e supervalorizar outras, como os fenômenos climáticos, tal dispositivo está atuando diretamente na forma como os habitantes das áreas de risco irão compreender a si e o contexto social no qual estão situados. Tais estratégicas de governamentalização (Foucault, 2008) fazem do risco um elemento que atua na biopolítica, reposicionando as pessoas nos territórios e incidindo diretamente sobre os modos de vida nesses contextos.

Ao destacar os elementos políticos e sociais que envolvem as pessoas expostas aos riscos de desastres, não estávamos em busca de medidas simples ou de cunho assistencialista, visto que a mera associação entre risco e pobreza pode gerar ainda mais exclusão e medidas de tendência autoritária e higienista, como apontam diversas(os) pesquisadoras(es) (Batista, 2010; Caliman \& Tavares, 2013; Hüning \& Guareschi, 2002). Por esses caminhos, o risco pode ser utilizado como parte de um dispositivo de controle e vigilância, escondido sob o manto da proteção, e sob a bandeira dos problematizáveis grupos de risco (Oliveira, 2011). Buscamos, contudo, ressaltar a complexidade que envolve o gerenciamento do risco no contexto das emergências e desastres, dadas as idiossincrasias do cenário pesquisado.

Considerando as questões apresentadas até o momento, destaca-se ainda que mesmo reconhecendo o papel que a defesa civil enquanto instituição apresenta na produção de discursos sobre o sujeito do risco, não podemos deixar de destacar as forças que atuam como vetores opostos a esse movimento. Os habitantes dos territórios em risco não são figuras passivas que sobrevivem ao sabor dos acontecimentos. Identificar as estratégias de gerenciamento que promovem autonomia, assim como os movimentos de resistência, é deveras importante para que possamos avançar no debate sobre a gestão de riscos e emergências.

Compreendemos que as múltiplas tentativas de gestão das pessoas a partir do controle e delimitação do território são também recebidas por movimentos de resistência, daqueles que compreendem a cidade a partir de seu valor de uso (Carlos et al., 2015). Essas resistências atuam como irregularidades

comportamentos, as maneiras de fazer dos produtores, dos compradores, dos consumidores, dos importadores, dos exportadores, integra-se ao mercado mundial" (Foucault 2008, p. 59). Nesse contexto, a segurança assume um papel regulador. que se distribuem ao longo das relações de poder, podendo produzir rupturas e desestabilizar os sistemas, sendo ainda, transitórias e, em muitos casos, precárias. Nessa perspectiva, não é possível estudar as engrenagens em que se estruturam as relações de poder sem apreender os processos de resistência que delas fazem parte e a elas se opõem, produzindo tensionamentos. Visibilizar os movimentos de oposição, de revolta, permite uma crítica aos "regimes de verdade", ao monopólio dos saberes, às respostas prontas nas distintas instâncias do social. Os movimentos de resistência reivindicam o direito de construir processos particulares de identificação e construção de subjetividades (Alvim, 2012).

Desse modo, é possível observar que nosso atual modelo de sociedade continua atualizando processos históricos de exclusão, construindo sua territorialidade na separação entre ricos e pobres e se negando a discutir a pobreza para além de questões meritocráticas e individualistas, promovendo uma alienação pública ante as reais práticas promotoras das desigualdades no país. Tal estratégia de governamentalidade (Foucault, 2008) apresenta a natureza como uma espécie de "bode expiatório", que tira o foco da negligência do Estado para com as vulnerabilizações da população e centra a problemática em elementos que são imprevisíveis: os fenômenos da natureza. Nesse sentido, compreender como (sobre)vivem as pessoas nos territórios em risco é uma importante estratégia de enfretamento dessa complexa conjuntura.

\section{Metodologia}

A pesquisa aqui apresentada utilizou uma metodologia de orientação qualitativa em Psicologia Social, tendo como proposta uma análise do discurso influenciada pelas concepções discursivas desenvolvidas por Michel Foucault e pela Psicologia Discursiva de orientação inglesa. Ambas as correntes de pensamento possuem como marca central a compreensão de que "Não é dentro de nossa mente que temos que 'olhar' para saber como pensamos, e sim devemos 'olhar' para nossos discursos, para o exterior" (Gracia, 2005, p. 27). Nesse sentido, a linguagem deixa de ser considerada como um simples instrumento de representação da realidade para ser pensada como um elemento ativo de invenção do social.

A perspectiva foucaultiana foi importante para observação do macrodiscurso, a partir de sua construção histórica, das relações que ele estabelece entre o 
saber, a verdade, o poder e os processos de subjetivação. Essa relação entre poder, verdade e discurso é um ponto central no tipo de análise de discurso que aqui buscaremos desenvolver, principalmente quando consideramos um contexto multiprofissional de atuação como a defesa civil, em que distintos saberes competem para determinar o que pode ou não ser considerado uma situação de risco. Foucault buscou descrever como o poder se transforma em um saber que, por sua vez, instala-se como verdade na sociedade (Foucault, 2013a, Foucault, 2014). Da Psicologia Discursiva trouxemos como principais referências sua ênfase sobre os microdiscursos da linguagem em processo de ação e interação. Consideramos ainda seu foco sobre a performatividade na produção discursiva, ou seja, os modos como os sujeitos constroem seus discursos e os efeitos que estes produzem sobre seus ouvintes (interlocutores) (Billig, 1991; Davies \& Harré, 2001; Gergen, 1985, 1999; Potter \& Wetherell, 1987).

Os discursos acessados e analisados foram construídos por meio de entrevistas semiestruturadas com pessoas usuárias do Sinpdec de quatro cidades da RMR. Nossa escolha por esse método ocorreu pela flexibilidade que o referido modelo permite, possibilitando um potente diálogo entre o entrevistado e o entrevistador. De acordo com Alves-Mazzotti e Gewandsznajder (2004), a característica interativa das entrevistas permite que temas complexos sejam abordados e explorados de forma mais aprofundada.

As(os) participantes foram identificadas(os) a partir de listagens de usuárias(os) do Sinpdec que recebem ou já receberam o auxílio-moradia ${ }^{4} \mathrm{e}$ convidadas(os) a colaborar com a pesquisa. Após o fornecimento da lista de contatos, as instituições participantes não receberam nenhum tipo de informação sobre quais pessoas aceitaram participar das entrevistas, nem sobre o local e a data em que estas aconteceram. Quinze pessoas, sendo doze mulheres e três homens, foram entrevistadas ${ }^{5}$. Para preservar a identidade das(os) envolvidas(os), no presente artigo, os nomes verdadeiros foram substituídos por fictícios.

Todas as entrevistas foram transcritas de forma literal, preservando o modo de falar de cada participante. Todas as falas e perguntas da entrevistadora também foram transcritas integralmente (Potter \& Wetherell, 1987). Essa busca por mostrar as distintas vozes em interação presentes nas entrevistas evidencia o aspecto polifônico do campo e traz a alteridade como seu fundamento, evidenciando possíveis tensões, conflitos e desencaixes. Para Souza e Carvalho (2016), "É através da alteridade que é possível fazer falar o interlocutor da pesquisa no texto - o que não corresponde a dar a voz, mas a dar espaço para a voz -, naquilo que ele enuncia a partir do seu lugar" (p. 105, grifos das autoras).

Para Minayo (2012), ordenar o material encontrado no campo e "impregnar-se" dele na tentativa de compreendê-lo são movimentos fundamentais para uma análise qualitativa. Também foi fundamental para o presente estudo o processo denominado pela autora como tipificação, o qual consiste em organizar os dados, recortá-los e agrupá-los conforme critérios de classificação. Tais processos são seguidos por novas leituras e, caso se julgue necessário, reestruturação dos critérios de classificação. Gill (2002) salienta, por sua vez, que na análise do discurso a ordenação dos dados não busca apenas examinar as regularidades do texto, mas também as variabilidades. Nesse sentido, à medida que os discursos foram sendo lidos, buscamos neles caminhos organizativos que nos auxiliassem a compreendê-los.

\footnotetext{
${ }^{4} \mathrm{O}$ auxílio-moradia é um benefício eventual concedido por alguns órgãos de defesa civil municipais e estaduais a famílias cujas residências foram avaliadas como estando em risco pela defesa civil e são consideradas impróprias para moradia. Além da avaliação estrutural dos imóveis, as condições socioeconômicas das(os) usuárias(os) também são consideradas para concessão do benefício, que é concedido apenas às pessoas que não possuem condições de alugar outro espaço ou abrigar-se em casa de parentes. O valor deve ser destinado ao aluguel de nova residência até que a família possa retornar ao local de origem ou receba uma nova moradia.

${ }^{5} \mathrm{O}$ presente projeto foi aprovado pelo comitê de ética e pesquisa com seres humanos, sendo registrado pela numeração: 1.052 .823 . Buscando ainda a proteção dos direitos das(os) envolvidas(os) nele, e conforme os aspectos éticos indicados pela Resolução n466/2012, do Conselho Nacional de Saúde, todas as entrevistas foram realizadas após as(os) entrevistadas(os) lerem e assinarem um termo de consentimento livre e esclarecido (TCL). Além do procedimento formal de assinatura do TCL, buscamos ratificar durante todo o nosso encontro a garantia do direito de nossas(os) participantes. Consideramos que qualquer entrevista é, por si só, uma ação intimidadora: o encontro com uma pessoa desconhecida, a assinatura de um documento formal, com a inclusão de número de documento, a necessidade da presença de duas testemunhas, além do gravador como elemento que captura o encontro; todos esses elementos podem gerar desconfortos na pessoa entrevistada. Nesse sentido, buscamos reforçar ao longo do encontro a garantia da confidencialidade, o direito de desistência em qualquer momento, inclusive nos dias posteriores à entrevista, e fornecemos contatos da pesquisadora e da própria universidade, para que possíveis dúvidas fossem suprimidas quanto à identidade das pesquisadoras e a formalidade da pesquisa.
} 


\section{Resultados e discussão}

Mesmo que não seja o objetivo do presente texto aprofundar o debate sobre o perfil dos participantes de nossa pesquisa, é importante ressaltarmos algumas informações. As(os) usuárias(os) do Sinpdec identificadas(os) em nosso estudo são em sua maioria do sexo feminino, com renda per capita de aproximadamente R\$ 166,10. Essas pessoas estão abaixo dos índices de desenvolvimento humano do estado de Pernambuco; apresentam uma renda abaixo da média; frequentaram a escola por menos tempo que a média; raramente trabalham com carteira assinada; e obtêm seu sustento por meio do trabalho informal e subsídios de programas sociais. As informações encontradas são corroboradas pelo índice Gini pernambucano -0,553e, em particular, do Recife $-0,68$, considerada pela $25^{\text {a }}$ vez a capital mais desigual do Brasil ${ }^{6}$.

As quinze entrevistas realizadas forneceram um rico material discursivo que foi sistematizado no presente estudo em dois grupos. No primeiro bloco de análises, apresentaremos e debateremos os relatos sobre os acontecimentos que levaram nossas(os) participantes a habitar as chamadas áreas de risco; no segundo bloco enfocaremos os movimentos de resistência, as estratégias de gerenciamento do risco desenvolvidas por essas pessoas, que vão de encontro aos modelos hegemônicos vigentes.

\section{Trajetórias de risco}

Um dos primeiros elementos que chamam atenção em nossa pesquisa são os percursos desenvolvidos pelas pessoas em busca de moradia. Muitos descreveram trajetórias de vida caracterizadas pela procura por habitações distantes dos inúmeros riscos que permeiam os territórios urbanos. Nossas(os) entrevistadas(os) se descrevem como pessoas que não possuem alternativas para habitar locais seguros; que foram morar em locais inseguros ou continuaram vivendo em zonas já classificadas pela defesa civil como estando em risco, por falta de recursos financeiros. Os recortes de entrevista a seguir são ilustrativos dessa questão:

Camila: aí nisso passei quase um mês procurando uma troca para sair de lá do D.7 que era muita vio- lência, aí não deu mais para ficar. Aí eu corri atrás de casa para alugar, aí foi nisso que eu encontrei um amigo lá no D. e tinha uma casinha na P., e aí nesse negócio eu peguei e fui, troquei com ele... Já em C., aí eu peguei e vim pra C. de novo, onde eu morava que eu já estava muito tempo acostumada ali morando na P., aí nisso eu troquei a casa e fui morar lá. Aí depois, de lá dessa casinha que eu fui morar passei para esse lado, que é o mesmo lado sabe, que fica um embaixo, outro também já sairam um bocado que perderam ali, aí eu subi para cima, a pessoa que eu estava morando ganhou uma casa, ganhou da prefeitura, teve sorte né de ganhar.

\section{Pesquisadora: $E$ a defesa civil já foi aí?}

Camila: Não, onde eu estou ainda não, mas antes de ir, eu moro ali já tinha ido, tem umas casas, tudo de X, como o pessoal mandava, um bocado de gente já saiu sabe? Só que a gente não teve onde morar e o sobrinho dele comprou lá, como comprou lá e morou uns poucos anos com a mulher que ele arrumou e não deu certo. Aí como ele não ter lugar certo é difícil vender, aí ele pediu para a gente ficar lá porque a gente não tinha condições de ficar pagando.

Pesquisadora: Ah, teve vizinho seu que depois que saiu voltou e...?

Camila: Voltou de novo para morar, que não teve condição de pagar aluguel e foi para lá morar de novo, gastou que só. "Menina, não adianta vocês voltar porque vai rachar", "mas só que eu não tenho onde morar Camila, eu tenho que voltar para o mesmo lugar". Olha tinha percevejo, tinha barata, tinha rato e elas moraram lá no meio, cada dia mais eu ia lá a casa rachando, "mulher não dá para tu ficar aqui, tem que dá um jeito", "eu não tenho como ir", "mas dá um jeito, procura qualquer coisa, vai para a casa de família", "não tenho", mas elas teimaram e foi, para lá foi e voltaram umas três pessoas morar ali, no mesmo lugar tem um jeito. Mesma a casa rachada, voltaram para aumentar, aí foi, tentaram morar, gastaram, ai quando foi esse ano rachou tudinho, quando veio a chuva pesada.

\footnotetext{
${ }^{6}$ A comparação entre os índices Gini das capitais foi realizada pela equipe do Jornal Diário de Pernambuco. http://curiosamente.diariodepernambuco.com.br/project/recife-capital-brasileira-da-desigualdade

${ }^{7}$ Apenas a primeira letra dos nomes de bairros citados pelas(os) participantes foi mantida nos discursos analisados.
} 
Entrevistadora: Como aconteceu o deslizamento?

Cecília: E quando a gente viu uma água na barreira, aí foi quando o meu vizinho gritou "está descendo água na barreira, corre", quando a gente disse "corre", se eu não tivesse puxado minhas duas filhas elas tinham morrido.

Entrevistadora: quando a defesa civil chegou, quais foram as orientações?

Cecília: Eles diziam que no momento, porque a minha casa já tinha um risco porque eu não tinha condições logo que eu me separei, tinha um risco de desabar por ser de maderito, aí o engenheiro me acompanhou sete anos, antes de acontecer esse deslizamento, aí já estava pretendendo me ajudar para construir a minha casa e arrumar uns tijolos, as coisas para construir, mas só que foi quando deslizou.

As entrevistadas apresentam discursos marcados pela exposição a inúmeros riscos, com destaque para aqueles causados pela falta de moradia em locais seguros. Camila constrói um discurso voltado para as dificuldades, para as perdas e para falta de alternativas de moradia, não de modo pontual, mas ao longo de sua história de vida. O recurso da descrição vívida, utilizado por ela para nos contar sua histórica, é definido por Potter (1998) como uma estratégia discursiva rica em detalhes contextuais e incidentes, frequentemente utilizada para demonstrar experiência perceptual e indicar que o falante tem um esquema particular de observação.

Camila utiliza ainda vários trechos de discurso direto (Potter, 1998), construções discursivas de outras pessoas que ajudam a fundamentar a ideia que ela desenvolve de que não está morando num imóvel próprio por falta de opções, para evitar novas situações de risco: "Menina, não adianta vocês voltar porque vai rachar"; "Mas, só que eu não tenho onde morar Camila, eu tenho que voltar para o mesmo lugar". Por meio do discurso de sua ex-vizinha, a usuária nos informa sobre a situação de vulnerabilização de uma das áreas de risco em que residiu, colocando ainda que outras pessoas estão na mesma situação, ou seja, esse não é um problema pontual, mas coletivo.

Nossas entrevistadas, mesmo que de modo não intencional, refutam a lógica vigente, presente em muitos textos e nos discursos de muitos profissionais da defesa civil, de que a população não compreende os riscos aos quais está exposta. Essas mulheres constroem um discurso sobre a pobreza, sobre a falta de alternativas diante dos riscos. Viver em áreas permeadas pela ameaça de deslizamento, por enchentes e desabamentos aparece como alternativa à convivência com alguns tipos de violência, como enfoca Camila, ou mesmo a total falta de um local para habitar. É interessante lembrar a afirmação de Billig (2008), segundo a qual, quando argumentamos, não estamos apenas defendendo uma posição, estamos combatendo argumentos alternativos que existem no interior de nosso meio social. Camila, mesmo que de modo implícito, argumenta que sua relação com o risco não é uma questão de capacidade de entendimento.

Spink (2014), transpondo os estudos sobre população com HIV/aids (Rhodes, 1995) para as pesquisas sobre o viver nas áreas de risco, utiliza o conceito de hierarquização dos riscos. Para a autora, as pessoas em seu cotidiano tendem a valorizar determinados fatores de risco em detrimento de outros, ou seja, diante da possibilidade de um desabamento ou deslizamento de terra e a iminência de estar em situação de rua, muitas famílias preferem continuar em locais classificados como estando em risco de desabamento, por exemplo. Nesse sentido, muito mais do que estar "subjetivamente imune ao risco" (Douglas, 1996) em decorrência de uma recorrente exposição a ele, as pessoas que encontramos ao longo de nosso estudo conseguem definir os riscos aos quais estão expostas, precisam, contudo, hierarquizá-los diante da multiplicidade de perigos vivenciados.

Tais observações são corroboradas ainda pela pesquisa realizada por Vargas (2009) com moradores das áreas de risco do estado de Minas Gerais, em que a autora afirma que:

O risco ambiental, exemplificado por deslizamentos de terra e enchentes se apresentará, então, apenas como mais um elemento componente do cenário de dificuldades e demandas imediatas, numa condição de quase insignificância frente a outros elementos presentes - mostra-se contornável e passível de convivência (Vargas, 2009, p. 81).

Nesse sentido, quando lidamos com a população que é público-alvo das políticas de defesa civil, precisamos compreender que existe o risco concreto de deslizamento, desmoronamento, desabamento de imóvel, seca ou enchente. Contudo, a questão habitacional, a 
falta de recursos materiais para sobreviver, entre outras problemáticas, muitas vezes são consideradas pelas comunidades afetadas como mais urgentes que as avaliações de risco trazidas pelos especialistas.

\section{Territórios de resistências}

Em nossa pesquisa trabalhamos com uma ideia de poder flexível, em que os jogos de verdade permitem o exercício de resistências e, por conseguinte, possibilitam aos sujeitos moverem-se, ocupando posições de mais ou menos poder (Foucault, 2004). Observamos ao longo das entrevistas, discursos sobre perda e abandono, mas também demonstrações de compreensão sobre os riscos, que esbarram em poucas possibilidades concretas para sanar o problema. Mapearemos, no presente tópico, algumas estratégias utilizadas pelas(os) moradoras(es) para reivindicar direitos e buscar modificações para o contexto de vulnerabilização em que vivem.

Identificar tipos de risco e solicitar ações por parte da defesa civil antes da ocorrência do sinistro foi uma dessas estratégias identificadas nos discursos das(os) usuárias(os). Os recortes de entrevista a seguir, em contraposição ao discurso institucional vigente de que as pessoas residem em áreas de risco por falta de conhecimento, sinalizam uma compreensão sobre os riscos e chamam atenção para os poucos recursos de gerenciamento disponibilizados:

Entrevistadora: Como foi esse primeiro contato com a Defesa Civil?

Raquel: Eu fui procurar parceria, procurei parceria e eles disseram que não tinha previsão de barreira, de fazer barreira na época que eu estava com dinheiro, eu tava juntando um dinheiro, tinha o apoio também lá do pai da minha filha, da mais nova, e aí a gente ia entrar com a mão de obra, né, e não tive êxito nenhum.

\section{Entrevistadora: Orçamento Participativo?}

Robson: Isso. Ele foi lá, e a gente assinou, fez um abaixo assinado dando prioridade às barreiras, eles fizeram pista, acabaram com o campo de futebole fizeram uma quadra, fizeram posto de saúde, fizeram uma melhoria, mas as barreiras continuam do mesmo jeito. Uma ou duas que eles fizeram. E a prioridade da gente era as barreiras porque a gente precisava. É isso que atrapalha, o ruimé isso.

Entrevistadora: Quer dizer que foi essa firma que fez esse corte, essa parte aberta aqui? É uma empresa de quê? A senhora sabe?

Janaína: É uma firma de transporte, parece, essas coisas de transporte de cargas, essas coisas. Lá na frente é o Fórum, atrás eles tampou e cavou a barreira. Aí deixou as casas, quase na beirinha da barreira.

A construção de muros de contenção é uma das ações para mitigações dos riscos mais almejada pelas pessoas que residem nas proximidades de barreiras com alto risco de deslizamento. Diferentemente das lonas plásticas, que são provisórias e degradam-se facilmente, as primeiras oferecem uma solução duradoura para a questão dos movimentos de massa. Alguns dos municípios pesquisados oferecem programas para a construção de muros de contenção em taludes em duas modalidades: a) obras de pequeno porte, realizadas quando o proprietário do imóvel fornece a mão de obra e a prefeitura disponibiliza acompanhamento especializado e material de construção; e b) obras de grande porte, quando a prefeitura é responsável por toda a realização da obra. O acesso a esses serviços é disputado, e poucas pessoas são contempladas.

Como podemos observar nas entrevistas de Raquel, Robson e Janaína, o acesso a esse tipo de recurso não é fácil. Descreve-se uma gestão do risco pouco atenta às queixas trazidas pelas(os) moradoras(es), sendo as obras realizadas a partir de prioridades estabelecidas pelos gestores, e os apelos da população, colocados em segundo plano. Ao não conseguir que suas soluções sejam efetivadas, algumas pessoas chegam a assumir os riscos e buscar soluções por conta própria. Janaína descreve uma situação em que moradores se reúnem e decidem fazer o acesso da comunidade em que residiam que, após a instalação de uma empresa na região, foi totalmente destruído.

A governamentalidade, no contexto pesquisado, apresenta-se também como uma ação de controlar a conduta do outro, interferir em seu campo de possibilidades de ação. O que se configura como resistência nesse cenário é justamente as margens de manobra que as pessoas produzem a essas tentativas de 
controle e de intervenção ameaçadora à dignidade humana. Para Freitas e Vale Neto (2009), “ A lógica governamental do Estado se constitui a partir de uma autopreservação que pode ou não se pautar a partir da perspectiva da dignidade humana" (p. 13).

Observamos ainda que a reivindicação por assistência não se deu apenas nos momentos de prevenção, o pós-acidente também se configurou, para algumas(uns) entrevistadas(os), como um período de lutas e barganhas. Em alguns casos encontramos pessoas que recusaram as ofertas iniciais realizadas pela defesa civil, por acreditarem não serem essas as melhores alternativas para suas famílias:

Raimunda: Exatamente, até porque como eu acabei de dizer, ele pode ter feito qualquer coisa, independente disso, ele tem o direito de receber o auxílio dele assim, quando ele sair, ele continuar recebendo e se sair a moradia, ele tem direito porque ele não invadiu, até porque ele foi cadastrado, ele foi cadastrado.

Raquel: No caso, eles disseram que era pra eu sair, né? Queriam me colocar num abrigo e eu disse não, porque eu tinha uma casa, né? O deslize não foi por conta da minha casa, né? Foi por conta do vizinho,e aí eu disse que não iria sair enquanto eu não tivesse um seguro, né? Uma segurança. Aí foi quando eles foram, pegaram meus documentos todinhos e aí disseram que eu ia receber o auxílio-moradia,

Entrevistadora: Vocês quando estavam lá na V., antes vocês já pensaram em sair de lá?

Ana: Eu já pensava, eu não gostava daquele lugar, eu tava lá porque meu pai tava lá, minha mãe tava lá, minha mãe também pensava em sair, meu pai não queria sair, não queria perder, porque era de herdeiro, de família. E aí ele: "Não, eu também tenho direito, não sei o quê". E aí eu: "Não, mas eu quero sair, eu não gosto daqui, e tal". Mas foi o tempo, o tempo tirou a gente de lá, graças a Deus.

Ruth: $E$ o resto tudo foi eu. Meu irmão veio aqui dar uma força na barreira, o rapaz aí debaixo é mestre de obra e tomou a frente da obra. . . . quando tava pronto eles vieram avaliar, sabe, mas até o negócio que eu falei para você dos duzentos reais que eu vou dar baixa, mas se eu disser que não, eu tô mentindo, agora por quê? Já deu pra você entender mais ou menos a minha situação. ... Pronto, então eu vou ser sincera com você, quando você ligou pra mim, eu fiquei pensando mais nessa questão assim. Eu pensei que alguém tivesse agindo assim por trás.

Nossas entrevistadas descrevem a dificuldade dos momentos posteriores ao desastre, em que é necessário barganhar por benefícios e exigir o cumprimento do encaminhamento que consideram mais adequado. Os discursos dessas mulheres nos fazem visualizar uma batalha em que uma das partes quer oferecer sempre o mínimo e a outra precisa lutar por seus direitos. O discurso de Raimunda é completamente marcado pela reivindicativa, pela reafirmação dos direitos - no caso, os direitos do filho, que após ter sido preso teve o auxílio-moradia cortado e deixou os demais familiares em situação de vulnerabilização. Esse caso demonstra a fragilidade das políticas intersetoriais, dos serviços que, ao não se comunicarem, deixam às pessoas atendidas a tarefa de criar pontes entre as políticas, na busca por seus direitos. Raquel descreve uma situação de barganha com os analistas de defesa civil, que orientam a moradora a ir para casa de parentes; após a negativa, oferecem um abrigo, local visto como precário pela maioria das(os) entrevistadas(os); e, apenas após a exigência da usuária, disponibilizam o auxílio-aluguel.

A entrevista de Ana nos mostra outro olhar ante a situação de desastre, encara o sinistro como possibilidade de saída do risco e melhoria de vida para a família. Aquilo que a princípio foi identificado como trauma, perda, desestrutura, foi visualizado também como um processo de ruptura: convencer o pai dos perigos do imóvel e deixar a situação de risco. Uma alternativa, mesmo que radical, para as reivindicações feitas pela comunidade para mitigação dos riscos.

Nesse ponto, observamos que as estratégias para alcançar o objetivo pretendido são as mais diversas em um contexto em que não se tem voz (Spivak, 2010). O discurso de Ana promove uma ruptura na forma de perceber os usuários e usuárias da defesa civil. Nossa entrevistada positiva um acontecimento e uma relação até então negativizada por todas as pessoas acessadas. Furlan (2013), debatendo as ideias de Butler, afirma que a visão de um sujeito flexível, que consegue interagir e produzir diante do contexto no qual está inserido, permite um processo de interação com as estruturas sociais que "tanto podem limitar 
como possibilitar estratégias de ação subversivas ou ressignificadoras" (Furlan, 2013, p. 400).

Outra ação promotora de descontinuidades e rupturas foi observada durante a entrevista de Ruth. $\mathrm{O}$ desejo de retornar à sua moradia, recorrente entre as(os) pesquisadas(os), fez com que a participante, mesmo recebendo o benefício de auxílio-aluguel, não deixasse o endereço de risco e decidisse reconstruir por conta própria o imóvel perdido. Apesar de não ter recebido o suporte técnico necessário, Ruth decidiu não esperar uma resposta por parte da defesa civil.

Nossas(os) entrevistadas(os) também apresentam uma visão crítica para com o Estado e suas ações para melhoria do contexto social:

Raimunda: Tem tantos prédios aí inacabáveis, esperando terminar para entregar e se você for lá na J. B., tem um conjunto habitacional inacabável ali, e poderia estar terminado, já poderia estar entregado às pessoas dos C., do C., de qualquer comunidade que está aguardando e eles dão $R \$ 200,00$, por que não termina?

Raquel: Eu acredito que tá sendo um desperdício, né, porque eu tô há três anos, eu poderia estar na minha casa, né, sairia mais barato pra eles se eles, pelo menos, arrumasse um terreno pra eu construir. Eu acho que é um gasto desnecessário que eles poderiam entregar a casa, enquanto tem muitas casas por aí pra serem entregues, né? E ninguém nem vê resultado, porque eu já fui em vários bairro e já vi essas casas em construção paradas e, muitos dizem, eu já fui na prefeitura e eles disseram que ali é da (Secretaria) habitacional, era pra pessoas que pagavam a Caixa (Econômica) e o que sobrasse era pras pessoas de auxílio-moradia, né. E a gente fica como? A gente não tem nenhuma facilidade.

Carlos: O que é 150 casas para o governo, são casas simples para entregar o povo durante cinco anos, enquanto o estádio de futebol em menos disso foi gasto milhões, você sabe, aqui em S. L. e está lá hoje, de vez em quando, às vezes perdido, tem um joguinho lá, realizado o jogo lá e está o quê? Os morcegos tomando conta da Arena, e aí? Não apareceram milhões para fazer aquilo lá? Não sei se eu estou falando demais, mas. . .
Raimunda, Raquel e Carlos nos fornecem um pouco da visão crítica de nossos participantes, de sua forma de posicionar o Estado como aquele que nega direitos básicos e redireciona os recursos públicos para obras que não são prioridade diante das demandas sociais da população. Raquel chega mesmo a questionar porque a prefeitura prefere passar anos pagando um benefício que não garante uma moradia definitiva, enquanto muitos dos programas sociais oferecidos pelo governo como o Minha Casa Minha Vida, por exemplo, não são acessíveis a toda população. A questão levantada pela entrevistada nos remete a algumas pesquisas (Braga, 2016; Carlos et al., 2015; Rodrigues, 2014; Rolnik, 2015; Rufino, 2016) que questionam a efetividade de determinados programas sociais que, até o momento, têm se mostrado mais lucrativos para as grandes construtoras do que proporcionado, de fato, a redução do déficit habitacional das parcelas mais pobres da população.

Além das iniciativas individuais para mobilização citadas anteriormente e da ação conjunta de Janaína e seus vizinhos, foram poucas as ações coletivas de reivindicação registradas durante as entrevistas. Trouxemos alguns exemplos nos trechos de discurso a seguir:

Maria: Então, as meninas já teve vez de falar para mim assim "vamos chamar a imprensa e falar porque C. está esquecido, os outros já ganharam casa, as pessoas com auxílio-moradia e a gente nada", eu disse "mas, não vai adiantar nada".É só a gente confiar em Deus, confia naquele lá de cima. O Senhor sabe. . . ele esperou cinco anos com as ferragens nos pés e tirou tudo, que foi um processo para tirar isso e nós nem tem as casas. Eu tenho esperança ainda de receber a minha casa. Mas muita gente assim, "bota não sei o que, coloca na justiça”, Mas, a justiça da gente é Deus,

Cecília: Conversou ainda com a promotora. Ela disse que vocês têm que ir ao longo, tem que vim aqui, marcar não sei para onde, para quem, "para a gente vê o que pode fazer", aí ficou da gente fazer uma visita a ela, mas não foi mais, a gente também não pode estar perdendo trabalho e a passagem já paga caro né, aí pronto. Nessa crise a gente não pode nem estar abusando muito. 
A imprensa e a justiça aparecem no discurso de nossas entrevistadas como órgãos associados à reivindicação, acionados quando o poder público não cumpre seu papel de modo satisfatório. As tentativas de mobilização coletiva, conforme as entrevistadas, são permeadas pela insegurança, pela desmobilização e pelo medo de algum prejuízo. Elas relatam que o processo de reivindicação pode trazer mais prejuízos do que benefícios, como perder algum direito, no caso de Maria, ou prejudicar-se por precisar faltar ao trabalho, no caso de Cecília. Nesse sentido, observamos o recurso ao divino, como tentativa de apelo diante da falta de assistência e descaso por parte daqueles que deveriam promover o cuidado. Para Vargas (2009), a busca pelas divindades, longe de ser interpretada como passividade, deve ser lida como um processo de "trocas simbólicas" (p. 86) com elas. Esse movimento é interpretado pela autora como estratégias de resistência que justificam a permanência das pessoas nos locais de risco. A autora aponta ainda que diante de situações como as vividas por nossas entrevistadas, recursos como a "saída" e a "voz" são alternativas não disponíveis para todas as pessoas, sendo descartadas na maior parte do tempo pelas camadas menos favorecidas da população, por considerarem os altos custos para viabilizar a saída dos locais de risco, ou mesmo as dificuldades de acesso aos processos judiciais.

Um último dado que chama nossa atenção foi a dificuldade de acesso que nossas(os) entrevistadas(os) apresentaram com relação a serviços públicos básicos. Quando questionamos quais serviços públicos além da defesa civil eram utilizados por elas(es), a saúde foi a mais citada, sendo indicada por doze das(os) quinze entrevistadas(os), porém recorrentemente associada à precarização e dificuldade de acesso. Para nossa surpresa, a assistência social foi citada apenas em uma das entrevistas, sendo associada à concessão do bolsa família.

Para Nascimento (2010), a articulação entre as diversas políticas que compreendem a esfera pública demanda um projeto amplo, que objetive realizar mudanças de práticas, padrões e valores, no tocante aos processos organizacionais das instituições públicas. Valencio e Valencio (2011), em suas análises sobre as ações de defesa civil no país, acrescentam que o elevado número de desastres socioambientais que afetam estados e municípios reflete, entre outras questões, a incapacidade que a instituição apresenta de desenvolver ações transversais e propositivas no âmbito das políticas setoriais. Essa falta de articulação entre as diversas políticas públicas foi característica presente no contexto pesquisado.

\section{Considerações finais}

A vida nos territórios em risco é permeada por fraturas, injustiças e (im)possibilidades de melhoria. Durante nosso estudo, observamos que nem sempre o acesso aos serviços públicos configura-se como garantia para as melhorias nas condições de habitabilidade e saída das áreas de risco. Tais problemáticas agravam-se ainda mais quando refletimos sobre o atual processo de crise social no qual se encontra o país, com o gritante desinvestimento do Estado em políticas sociais, que se movimentam no sentido da perda de direitos e agravamento da já alarmante desigualdade social na qual vivemos.

Aos profissionais, psicólogos ou não, que desejam intervir e contribuir no debate sobre a gestão de risco e desastres já não cabe mais tratar a temática como exclusivamente atrelada a fatores meteorológicos/ambientais. A questão social não é uma temática transversal, ela atravessa e produz marcas profundas naquilo que se define como risco e, por conseguinte, na vida das pessoas que habitam os territórios permeados por ele.

Tais questões são trazidas pelas(os) entrevistadas(os) de modo contundente quando sinalizam que acessar o Sinpdec não assegura a mudança efetiva de sua condição habitacional, garante uma inclusão que também é excludente. Pois os riscos são nomeados, mas, na maioria dos casos, o gerenciamento dessas questões é delegado aos próprios moradores das ditas áreas de risco. Estar incluído em um processo que também é de exclusão foi o cenário que encontramos em nossa pesquisa. Observa-se isso, também, quando a assistência fornecida pelo Sinpdec não garante o acesso às demais políticas existentes no município. Dito de outra forma, quando o risco não é trabalhado em suas múltiplas dimensões, os demais atores que poderiam auxiliar em sua mitigação não são devidamente acionados.

Sobre as diversas estratégias descritas pelas(os) usuárias(os) para enfrentar os riscos vivenciados, não identificamos em seus discursos registros de mobilizações coletivas mais estruturadas, como associações de bairro, participação em grupos políticos ou 
qualquer outra iniciativa do tipo. Contudo, observamos que essas pessoas conseguem fazer uma crítica do contexto de exclusão social no qual vivem e questões como o déficit habitacional e a falta de políticas para promoção de moradias seguras estão presentes em seus discursos, ou seja, essas pessoas não reproduzem acriticamente a retórica do risco promovida por muitos especialistas da área.
Refletir sobre os riscos no contexto das emergências e desastres implica compreendê-los a partir de uma conjuntura complexa. Problematizar a situação de extrema precariedade na qual vivem as pessoas dos territórios em risco, viabilizar estratégias para que essas possam acessar seus direitos sociais básicos e assim se figurem como cidadãs e cidadãos de direito é uma tarefa que certamente fará diferença entre viver ou morrer nos territórios em risco.

\section{Referências}

Alves-Mazzotti, A. J., \& Gewandsznajder, F. (2002). O método nas ciências naturais e sociais: pesquisa quantitativa e qualitativa. São Paulo, SP: Pioneira Thomson Learning.

Alvim, D. M. (2012). Foucault e o primado das resistências. Cadernos de Ética e Filosofia Política, 20, 22-30.

Batista, V. M. (2010). A governamentalização da juventude: policizando o social. Epos, 1(1), 1-20.

Bert, J.-F. (2013). Pensar com Michel Foucault (M. Marcionilo, Trad.). São Paulo, SP: Parábola.

Billig. M. (1981). Ideology and opinions: studies in rhetorical psychology. London: Sage.

Billig. M. (2008). Argumentando e pensando: uma abordagem retórica a psicologia social (V. L. M. Joscelune, Trad.). Petrópolis, RJ: Vozes.

Braga, R. (2016). Indicadores de sustentabilidade para avaliação de zonas especiais de interesse social (ZEIS) para implantação de habitação social na cidade de Piracicaba-SP. Caderno de Geografia, 26(46), 464-485.

Brandão, J. M., Mahfound, M., \& Gianordoli-Nascimento, I. F. (2011). A construção do conceito de resiliência em psicologia. Paidéia, 21(49), 263-271.

Brasil. (2017). Glossário de proteção e defesa civil. Brasília, DF: Ministério da Integração Nacional.

Caliman, L.V., \& Tavares, G. M. (2013). O biopoder e a gestão dos riscos nas sociedades contemporâneas. Psicologia: Ciência e Profissão, 33(4), 934-945.

Carlos, A. F. A., Volochko, D., \& Alvarez, I. P. (Orgs.). (2015). A cidade como negócio (pp. 165-208). São Paulo, SP: Contexto.

Centre for Research on the Epidemiology of Disaster \& United Nations Office for Disaster Risk Reduction. (2016). Poverty \& death: disaster mortality (1996-2015). http://www.unisdr.org/files/50589_creddisastermortalityall finalpdf.pdf

Conselho Federal de Psicologia. (2013). Nota Técnica sobre a atuação de psicóloga(o)s em situações de emergências e desastres, relacionadas com a política de Defesa Civil. Brasília, DF: CFP.

Davies, B., \& Harré, R. (2001). Positioning: the discursive production of selves. In M. Wetherell, S. Taylor \& S. J. Yates (Orgs.), Jornal for the theory of social behavior (Vol. 20, pp. 43-65). London: Sage.

Douglas, M. (1996). La aceptabilidad del riesgo según las ciencias sociales (V. A. Martínez, Trad.). Barcelona: Paidós.

Escola Nacional de Saúde Pública Sérgio Arouca. (2013). O mundo hoje e os desastres. http://andromeda.ensp. fiocruz.br/desastres/content/o-mundo-hoje-e-os-desastres/page/0/4/

Foucault, M. (2004). A ética do cuidado de si como prática de Liberdade. Ditos e escritos V: ética, sexualidade e política. Rio de Janeiro, RJ: Forense Universitária.

Foucault, M. (2005). Microfísica do poder (R. Machado, Trad., 21a ed.. Rio de Janeiro, RJ: Graal.

Foucault, M. (2008). Segurança, território, população (E. Brandão, Trad.). São Paulo, SP: Martins Fontes.

Foucault, M. (2013a). A ordem do discurso (L. F. A. Sampaio, Trad., 23a ed.). São Paulo, SP: Loyola.

Foucault, M. (2013b). O sujeito e o Poder. In H. L. Dreyfus \& P. Rabinow, Michel Foucault: uma trajetória filosófica. Para além do estruturalismo e da hermenêutica (V. Portocarrero \& G. G. Carneiro, Trads., 2a ed., pp. 273-295). Rio de Janeiro, RJ: Forense Universitária. 
Foucault, M. (2014). A arqueologia do saber (L. F. B. Neves, Trad., 8a ed.). Rio de Janeiro, RJ: Forense Universitária.

Franco, M. H. P. (2005). Atendimento psicológicos para emergências em avião: a teoria revista na prática. Estudos de Psicologia, 10(2), 177-180.

Freitas, A. S., \& Vale Neto, J. P. (2009). Governamentalização e criminalização da pobreza: constituição do discurso jornalístico sobre um bairro do Recife em três décadas (Diário de Pernambuco, 1970-2000). In Anais do $7^{\circ}$ Encontro Nacional de História da Mídia - mídia alternativa e alternativas midiáticas, Fortaleza, CE.

Freitas, C. M., Carvalho, M. L., Ximenes, E. F., Arraes, E. F., \& Gomes, J. O. (2012). Vulnerabilidade socioambiental, redução de riscos de desastres e construção da resiliência: lições do terremoto no Haiti e das chuvas fortes na Região Serrana, Brasil. Ciência \& Saúde Coletiva, 17(6), 1577-1586.

Furlan, N. (2013). Sujeito e agência no pensamento de Judith Butler: contribuições para a teoria social. Sociedade e Cultura, 16(2), 395-403.

Gergen, K. J. (1985). The social constructionist movement in modern psychology. American Psychologist, 4(3), 266-275.

Giddens, A. (1991). As consequências da modernidade (R. Fiker, Trad.). São Paulo, SP: Unesp.

Gill, R. (2002). Análise do Discurso. In M. W. Bauer \& G. Gaskell (Eds.), Pesquisa qualitativa com texto, imagem e som (P. A. Guareschi, Trad., pp. 244-270). Petrópolis, RJ: Vozes.

Gracia, T. I. (2005). O giro linguístico. In L. Iñiguez, Manual de Análise do discurso em ciências sociais (V. L. Joscelyne, Trad., 2a ed., pp. 19-49). Petrópolis, RJ: Vozes.

Hüning, S. M., \& Guareschi, N. M. F. (2002). Tecnologias de governo: constituindo a situação de risco social de crianças e adolescentes. Currículo sem Fronteiras, 2(2), 41-56.

Koga, D. R. C. (2009). O impacto dos fenômenos climáticos sobre a organização e dinâmica sócio-produtiva num assentamento rural: estudo de caso do efeito das chuvas no assentamento "Bela Vista do Chibarro", em Araraquara/SP. In N. Valencio, M. Siena, V. Marchezini, \& J. C. Gonçalves, Sociologia dos desastres: construção, interfaces e.perspectivas no Brasil (pp. 119-130). São Carlos, SP: Rima.

Minayo, M. C. S. (2012). Análise qualitativa: teoria, passos e fidedignidade. Ciência \& Saúde Coletiva, 17(3), 621-626.

Ministério da Integração Nacional. (2014). Anuário brasileiro de desastres naturais: 2013. Brasília, DF: Cenad.

Nascimento, S. (2010). Reflexões sobre a intersetorialidade entre as políticas públicas. Serviço Social e Sociedade, $101,95-120$.

Oliveira, M. L. (2011). A gestão dos riscos nas políticas de Juventude: um estudo a partir dos egressos do ProJovem. Recife, PE: Universitária.

Paulino, J. A., \& Lopes, R. F. F. (2010). Relação entre percepção e comportamento de risco e níveis de habilidades cognitivas em um grupo de adolescentes em situação de vulnerabilidade social. Psicologia ciência e Profissional, 30(4), 752-765.

Potter, J. (1998). Representing reality: Discourse, rhetoric and social construction. London: Sage.

Potter, J., \&Wetherell, M. (1987). Discourse and social psychology: beyond attitudes and behaviour. London: Sage.

Rhodes, T. (1995). Theorizing and researching "risk": notes on the social relations of risk in heroin users' lifestyle. In P. Aggleton, P. Davies, \& G. Hart (Eds.), AIDS: safety, sexuality and risk (pp. 125-143). London: Taylor \& Francis.

Rodrigues, R. (2014). Moradia popular: a cidade em disputa. Caros Amigos, 208, 5-8).

Rolnik, R. (2015). Guerra dos lugares: a colonização da terra e da moradia na era das finanças. São Paulo, SP: Boitempo.

Rufino, M. B. C. (2016). Transformação da periferia e novas formas de desigualdades nas metrópoles brasileiras: um olhar sobre as mudanças na produção habitacional. Cadernos Metrópole, 18(35), 217-236.

Silva, J. C. B. (2017). Muito além da questão ambiental: discursos sobre as gestões dos riscos no contexto das emergências e desastres (Tese de doutorado). Universidade Federal de Pernambuco, Recife, PE.

Silva, J. C. B., \& Menezes, J. A. (2016). Reflexões sobre a inserção do profissional de psicologia nas equipes multiprofissionais de defesa civil. In C. L. B. T. Barreto, A. L. Francisco, \& S. D. B. Walckoff (Orgs.), Prática psicológica em instituição: diversas perspectivas. Curitiba, PR: CRV.Sluzki, C. E. (1997). A rede social na prática sistêmica: alternativas terapêuticas. São Paulo, SP: Casa do Psicólogo. 
Souza, M. T. S. (2011). Resiliência e desastres naturais. Ciência e Cultura, 63(3), 4-5. https://dx.doi.org/10.21800/ S0009-67252011000300002

Souza, S. J., \& Carvalho, C. S. (2016). Ética e pesquisa: o compromisso com o discurso do outro. Polis e Psique, $6(1), 98-112$.

Spink, M. J. (2014). Viver em áreas de risco: tensões entre gestão de desastres ambientais e os sentidos de risco no cotidiano. Ciência \& Saúde Coletiva, 19(9), 3743-3754.

Spink, M. J., Pereira, A. B., Burim, L. B., Silva, M. A., \& Diodato, P. R. (2008). Usos do glossário do risco em revistas: contrastando "tempo" e "públicos". Psicologia: Reflexão e Crítica, 21(1), 1-10. http://www.scielo.br/pdf/prc/ v21n1/a01v21n1.pdf

Spivak, G. C. (2010). Pode o subalterno falar? (S. R. G. Almeida, M. P. Feitosa, \& A. P Feitosa, Trads.). Belo Horizonte, MG: Editora UFMG.

Valencio, N. (2010). Desastres, ordem social e planejamento em defesa civil: o contexto brasileiro. Saúde Sociedade, 19(4), 748-762.

Valencio, N., Siena, M., Marchezine, V., \& Gonçalves, J. C. (Orgs.). (2009). Sociologia dos desastres: construção, interfaces e perspectivas no Brasil. São Carlos, SP: Rima.

Valencio, N., \& Valencio, A. (2011). Os desastres como indícios da vulnerabilidade do sistema nacional de defesa civil: o caso brasileiro. Territorium, 18, 147-156.

Vargas, D. (2009). "Eu fui embora de lá, mas não fui”: a construção social da moradia de risco. In N. Valencio, M. Siena, V. Marchezine, \& J. C. Gonçalves (Orgs.), Sociologia dos desastres: construção, interfaces e perspectivas no Brasil (pp. 80-95). São Carlos, SP: Rima.

Veiga-Neto, A. J. (2007). Foucault \& a educação. Belo Horizonte, MG: Autêntica.

Vieira, R. (2004). Um olhar sobre a paisagem e o lugar como expressão do comportamento frente ao risco de deslizamento (Tese de doutorado). Universidade Federal de Santa Catarina, Florianópolis, SC.

\section{Juliana Catarine Barbosa da Silva}

Professora adjunta do curso de Psicologia da Universidade de Pernambuco. Doutora em Psicologia pela Universidade Federal de Pernambuco. Pesquisadora do Grupo de Estudos e Pesquisas sobre Poder, Cultura e Práticas Coletivas (Gepcol), Recife - PE. Brasil.

E-mail:jucatarine@gmail.com

(1) https://orcid.org/0000-0002-1632-3424

\section{Jaileila de Araújo Menezes}

Professora doutora do Departamento de Psicologia e Orientações Educacionais do Centro de Educação e do Programa de Pós-Graduação em Psicologia da Universidade Federal de Pernambuco. Pesquisadora do Grupo de Estudos e Pesquisas sobre Poder, Cultura e Práticas Coletivas (Gepcol), Recife - PE. Brasil.

E-mail: jaileila.araujo@gmail.com

(1) http://orcid.org/0000-0003-3322-3764

Endereço para envio de correspondência:

Rua João Rosendo, 220, Apto. 105, Cordeiro. CEP: 50731-090. Recife - PE. Brasil.

Recebido 12/01/2018

Aceito 13/05/2019

Received $12 / 01 / 2018$

Approved 13/05/2019

Recibido 12/01/2018

Aceptado 13/05/2019 
Como citar: Silva, J. C. B., \& Menezes J. A (2020). Discursos (Sobre)Viver nos Territórios em Risco da Região Metropolitana do Recife. Psicologia: Ciência e Profissão, 40, 1-17. https://doi.org/10.1590/1982-3703003190105

How to cite: Silva, J. C. B., \& Menezes J. A (2020). Speeches (About) Living in the Territories at Risk of the Metropolitan Region of Recife. Psicologia: Ciência e Profissão, 40, 1-17. https://doi.org/10.1590/1982-3703003190105

Cómo citar: Silva, J. C. B., \& Menezes J. A (2020). (Sobre)Vivir en los Territorios en Riesgo de la Región Metropolitana de Recife. Psicologia: Ciência e Profissão, 40, 1-17. https://doi.org/10.1590/1982-3703003190105 